\title{
The world-systemic network of global elite sociology: the western male monoculture at faculties of the top one-hundred sociology departments of the world
}

\author{
Marton Demeter ${ }^{1}$ (D) Tamas Toth $^{2}$
}

Received: 4 March 2020 / Published online: 17 June 2020

(c) The Author(s) 2020

\begin{abstract}
In this paper, we analyze the educational paths and networks of core staff members $(n=3325)$ of the world's top 100 sociology departments. Results show that a significant overrepresentation of central countries and considerable gender bias can be found throughout sociology departments with strong male dominance in high positions. By using an improved word-systemic model for the interpretation of our data, we were able to categorize the main agents and patients in the world-system of global elite sociology, and we could also describe those centripetal and centrifugal forces that absorb and reeducate peripheral talent while excluding those without Western reeducation.
\end{abstract}

Keywords Global sociology · Sociology of sociology $\cdot$ Knowledge colonialism · Worldsystem theory $\cdot$ Field theory

\section{Introduction}

Internationalization, that is the core concept of a neoliberal and global university, (Herschberg et al. 2018) has become a norm that most universities strive for. The main features of internationalization include, among others, an international curriculum, inward and outward student and staff mobility, and engagement with international networks and collaboration (Ennew and Greenaway 2012). While the above-mentioned features of the global academy hold for all disciplines, sociology is a unique field of research, in the sense that it not only adopts the law of internalization but also reflects this global process directly. It is not a surprise then that scholars from different areas of social sciences like Merton (1968), Prebisch (1959), Price (1965) or Bourdieu (1988) started to systematically analyze the structure of globalized and internationalized science, and research trends

Marton Demeter

Demeter.Marton@uni-nke.hu

Tamas Toth

toti088@gmail.com

1 National University of Public Service, Budapest, Hungary

2 Corvinus University, Budapest, Hungary 
with focus on the power relations of the global academy are still in the frontline (Bonitz et al. 1997; Curry and Lillis 2018; Demeter 2017; Efranmanesh et al. 2017; Heilbron et al. 2018; Moody 2004; Shenhav 1986; Zanotto et al. 2016). While most of these authors dealt with global inequalities regarding academic publication, other kinds of serious inequalities have also been investigated: Lauf (2005) and Demeter (2018a) analyzed the uneven global distribution of editorial board members in academic journals, and they both found a biased national diversity in journal editorial boards that correlate to a disproportioned national diversity in publication. In other respects, Boncourt (2018) found serious global inequalities regarding the national diversity of the International Sociological Association (ASA) and the International Political Science Association (IPSA), and similar biases were found in the case of the International Communication Association (Wiedemann and Meyen 2016). In the case of global science output, the composition of editorial boards and international associations, a common feature was found. Internationalization that is, theoretically, "the exchange of people, ideas, goods and services between two or more nations and cultural identities" (Wu and Zha 2018: 1) turned out to be Americanization (Wiedemann and Meyen 2016) or Europeanization (Wallerstein 2006), the two terms being interchangeable, as they both refer to the hegemony of the global North over the developing global South.

Despite the fact that faculties at leading higher education institutions play a critical role in shaping the face of the global academy, most research papers that deal with the structure of university faculties remain on a national (typically US) level when analyzing hiring tendencies of leading departments. In terms of recruitment policy, universities face a dual challenge: one is the problem of excellence and the other is the issue of internationalization. Regarding the first, departments must recruit the most productive employees in order to boost the research output of the institution that is measured by all prestigious university rankings (Pietrucha 2018). Regarding the second, departments must recruit an internationally-diverse faculty in order to agree with the concept of a neoliberal and global university (Ennew and Greenaway 2012; Herschberg et al. 2018). Thus, the classical view holds that universities, or more precisely, selection committees hire an extraordinarily productive and internationally diverse staff (Burris 2004; Tomlinson and Freeman 2018). However, as an extensive number of research projects show, this conventional view is far from being true. Instead of being a purely meritocratic selection process (Merton 1968), hiring turned out to be a social procedure full of nonmeritocratic factors (Clauset et al. 2015). Many researchers ascertained, for example, that the prestige of being affiliated with a given candidate's Ph.D. school could determinate her chances for a tenure track position to a much greater extent than her productivity would (Baldi 1994; Burris 2004; Clauset et al. 2015; Cowan and Rossello 2018; Cret and Musselin 2010; Enders 2001; Long et al. 1979; Maliniak et al. 2018; Smith et al. 2004; Tomlinson and Freeman 2018; Williamson and Cable 2003). The function that the prestige of the alma mater plays in the career trajectories of future academics is extraordinarily strong: Burris showed that "the prestige of the department in which an academic received a Ph.D. consistently ranks as the most important factor in determining the employment opportunities available to those entering the academic labor market" (Burris 2004: 239).

Current research has found a twofold motivation behind the positive discrimination towards candidates from elite education as delineated above. The first could be explained by the stratification hypothesis that suggests hiring patterns follow a strict hierarchy in order to establish a rank-based hiring network between top universities. Through this hierarchy, elite institutions play a win-win game where the sending university, viz. the one from which the candidate earned her Ph.D., will be highly ranked by the fact that another elite institution is willing to hire its Ph.D. graduates. In return, the sending university also 
highly rates the terminal institution, viz. the university where its Ph.D. graduate applies for a position, because it considers this university to be worth working for. In short, this bilateral positive assessment allows top universities to establish a top-tier core while excluding the rest (Clauset et al. 2015; Cowan and Rossello 2018; Maliniak et al. 2018). The second motivation behind this phenomenon is the assumption that the prestige of the candidates' $\mathrm{Ph} . \mathrm{D}$. institution and mentor will positively affect the future productivity of its applicants (Cret and Musselin 2010). However, empirical results clearly contradict this assumption. Williamson and Cable (2003) systematically analyze every possible correlation between the constituents of hiring processes and found that neither the academic origin nor the dissertation advisor play a significant role in future productivity. In terms of future scientific output, the only predictive factor was the applicants' past productivity—but, as it has been showed earlier, "pre-employment productivity has little if any impact on the prestige of the first position even though it is the best predictor of future productivity" (Long et al. 1979: 818). Through these two features of academic hiring delineated above, we can get a picture of a very clear and presumably detrimental discrimination pattern. Elite institutions mutually hire each others' candidates-almost irrespectively of their merits in terms of productivity, while systematically excluding academics without prestigious degrees, again, irrespectively of their merits despite the fact that future productivity could be anticipated by past productivity alone, and not by the prestige of the person's past academic degrees (Baldi 1994; Fumasoli et al. 2015; Long 1979; Long et al. 1979; Mussellin 2004; Williamson and Cable 2003). In conclusion, we can add to well-known factors, serious disadvantages such as non-Anglophone origin (Anderson 2013; Curry and Lillis 2018; Thompson and Diani 2015) or a working-class family background (Ball et al. 2003; McDonough and Fann 2007). Research shows that not being educated at one of the top-tier universities is a drawback that is extraordinarily hard to tide over (Bourdieu 1996; Cowan and Rossello 2018; Gerhards et al. 2017). Researchers also observed that the ruling elite systematically build and maintain an educational system by which the candidates from lower classes are purposely excluded from top positions. This process has built up a new stratification where - through the mediation of education - the elite could stabilize its hegemony over the members of other social classes (Bourdieu 1996). Empirical research also shows that while the number of enrolled students has grown consistently since the 1960s with the so-called worldwide expansion of global higher education (Schofer and Meyen 2005), the number of students who are educated in the elite universities remained unchanged. In this way, the elite is able to reproduce itself by the mediation of elite education (Bourdieu 1996).

As we have seen earlier, internationalization might be an egalitarian process theoretically, but empirically it could serve as an instrument of maintaining or even intensifying global inequalities (Ennew and Greenaway 2012; Marginson 2007). Amongst the most important risks referred to by researchers are brain drain (Mahroum 2002), the loss of cultural identities, the commodification of education through the advent of degree mills, and it is maintained that these risks threaten mostly the developing world (Altbach 2010; Canagarajah 2002; Egron-Polak 2012).

Recognizing the clearly hierarchical structure of the global academy made theories using core-periphery differentiation rather useful in analyzing power relations in this field of research. Clauset et al. (2015) analyzed American departments by network science methods and found that "the close proximity of the core to the entire network implies that ideas originating in the high-prestige core, regardless of their merit, spread more easily throughout the discipline, whereas ideas originating from low-prestige institutions must filter through many more intermediaries." (Clauset et al. 2015: 4). In a 
more international context, researchers started to use Immanuel Wallerstein's world systems theory to analyze internationalization processes.

This developing school of thought rejects the interpretation of globalization as a homogenizing or equalizing force and insists on re-connecting it with the processes of imperialism and cultural domination [...] The result is a theory of the global system of knowledge production which operates in a similar way to other aspects of the economic system. Just like the latter, it is hierarchical, infused with the relations of power, and characterized by a fundamentally unequal relationship between the intellectual 'core' and its periphery.

It was Wallerstein indeed who conducted systematic analyses that dealt with coreperiphery power relations in global institutions. Building on the earlier recognition of Marxist sociology and dependency theories, Wallerstein applied the concept of unequal exchange in many fields of social reality and stated that "the axial division of labor of a capitalist world-economy divides production into core-like products and peripheral products" (Wallerstein 2004: 28). He also maintained that core-periphery relations are related to real geographical positions and such that in "any given time there exist concentration of more highly capitalized, higher-wage, higher-profit activities in some places (core) and less capitalized, lower-wage, lower-profit activities in others (periphery)" (Wallerstein 1983: 17). Wallerstein regards science as a means of soft power since it is a "domain of justifying the legitimacy of power in the modern world" and the author adds that "scientism has been the most subtle mode of ideological justification of the powerful" Wallerstein 2006: 77). Finally, and most importantly, Wallerstein maintained that Western hegemony over the global South is characteristic mostly in the case of social sciences.

Social science has been Eurocentric throughout its institutional history, which means since there have been departments teaching social science within university systems. This is not in the least surprising. Social science is a product of the modern worldsystem, and Eurocentrism is constitutive of the geoculture of the modern world. Furthermore, as an institutional structure, social science originated largely in Europe. We shall be using "Europe" here more as a cultural than as a cartographical expression; in this sense, in the discussion about the last two centuries, we are referring primarily and jointly to western Europe and North America. (Wallerstein 1999:168).

Later researchers applied the Wallersteinian theory to the domain of the global academy in many ways. Salager-Meyer (2008) investigated global scientific publishing trends, Nordensvard et al. (2018) analyzed power structures in global innovation networks, while the contribution of Larson (2018) is more theoretical. The latter author-building on former results of Collyer (2014) - designed the structure of the global academy as a well-functioning core-periphery system in which the core exports linguistic, material and epistemic normativity through the determination of received theories and methods, while the dependent periphery provides raw material in the form of data and fresh labor force. In a global system of the internationalized academic community "the peripheries' role is to supply data to the core, where data are processed, producing theory and methodology that are, in turn, exported to the peripheries in the form of literature, and research and publication conventions" (Larson 2018: 523). Finally, we have Schott's research (1998), which observes that global science could be conceived as a network of its agents, and world-systems theory is a perfect explanation frame for the analysis of the main ties between the participating agents. He pointed out the most important processes by which the field of global 
academy maintains its hegemonic structure and he also successfully identified the differences between the capital accumulation of central, semi-peripheral and peripheral regions of the world.

World-systemic theoretical approaches are most frequently used when discussing global political or economic issues, but world polity research, which is often considered to be a derivation of world-system theory, assumes the existence of world-systems that rely on other features than economic or military power (Cole 2017; Meyer et al. 1997; Thomas et al. 1987). This tradition maintains that different—collective or individual—social agents are "embedded in and shaped by a global cultural, social, and political environment, resulting in a great deal of decoupled isomorphism among them" (Cole 2017: 86). The theory of world polity considers research institutions and curricular content as typical examples of cultural patterns which follow global or allegedly universal scripts (Meyer et al. 1992). Another research tradition dealing with global inequalities in science is decolonialization theory (Kerr 2014; Mignolo 2011, 2018; de Sousa Santos 2007, 2018). Sousa-Santos uses the very expressive word epistemicide when referring to the fact that hegemons of global science systematically exterminate rival or simply alternative research traditions, epistemologies, and peripheral knowledge. This phenomenon was also measured on a European level (Bennett 2015). According to this tradition, the so-called globalization of knowledge is conceived as an encounter of cultures which implies the death of the subordinated participant's knowledge. This leads to an epistemic monoculture (Mignolo 2011) where the West maintains control over the structure of knowledge. According to decolonialization theorists, the global academic community needs a cognitive justice in which the norm is the plurality of knowledge and that even peripheral members of the community have the right to different forms of knowledge (de Sousa Santos 2007).

Besides the Wallersteinian analysis and decolonialization theories that deal with geographical stratification of power relations, there are also models that analyze the intersocietal and institutional stratification of social hegemonies. Bourdieu (1996) and his successors (Demeter 2018b; Gerhards et al. 2017) systematically analyzed the world of the academy to assess power relations and class stratification in education and academic recruitment. They found that the elite strategically constructed an education system by which they could rule over students from lower classes. In this sense, national education serves as a masking tool that helps maintain the hegemony of the national elite, while international elite institutions serve the interests of the international elite against mass education in the background, which has been constructed for the masses from lower classes (Gerhards et al. 2017). From this perspective, we may conclude that we have two types of centrality, and therefore two types of peripherality. The first refers to geographical positions, typically described as the central core versus the periphery or the global North versus the global South, while the second refers to social positions and the struggle between the lower classes and the elite. In this paper, we suggest a three-dimensional analytical model that is capable of describing both types of central-peripherality where the first two horizontal dimensions refer to geographical positions while the third, vertical dimension relates to the agents' class position in terms of their academic positions in a three-level hierarchy. However, as we will argue later, these dimensions are tightly interwoven, with the transnational academy being a global network, for example, international human capital (accumulated in the form of elite education) may be collected at the geographical center almost exclusively, so that students and candidates from less mobile lower classes in the periphery could not acquire it, and as a consequence, we might find more central agents in top positions, while peripheral agents would be more frequent in lower academic statuses. Consequently, we used our research to measure social stratification as it is represented in 
academic stratification, which refers to a three-level hierarchy, as we will explain in detail in our methods section.

In this research, we will use the three-dimensional model delineated above for the interpretation of our empirical data regarding faculties' career paths and their current positions which we have gathered from the top 100 sociology departments in the world. We will investigate how social stratification represented in academic positions of different hierarchical status and geographical placement affect the composition of elite global sociology in terms of research and teaching staff. We will also measure the academic stratification by the proportion of women in different academic positions, since they are the most typical periphery-within-the-core social group to analyze (Wallerstein 2006), while geographical position shifts will be analyzed by the education trajectories of leading sociologists. The contribution of this analysis is twofold. First, it will show a clear and empirically underpinned picture of the internationalization processes in global sociology by presenting the accumulation of academic capital in top sociology departments (Bourdieu 1988; Wallerstein 2004). Second, it will be the first attempt to apply a modified version of world systems theory for the interpretation of extensive empirical data on career trajectories. Our paper contributes to existing literature by both presenting and theoretically explaining one of the most fundamental questions in current and future sociology within an academic context: who conducts, controls and shapes global sociology and why are they the chosen ones?

Based on the assumptions of existing literature we pose four hypotheses for empirical testing.

H1 In terms of academic capital (measured in university degrees), the field of global sociology is strongly stratified and only slightly international.

H2 The process of brain drain is at work within the field so that the internationalization level decreases from BA to Ph.D. degrees.

H3 The picture of global sociology demonstrates a center-periphery structure in terms of both the participation of peripheral groups and the accumulated academic capital.

H4 Some intermediates would emerge and constitute the semi-periphery of the field of global sociology.

\section{Methods}

Our first step is to build the database of sociology core staff members at the top 100 universities. For this purpose, we used to THE QS World University Rankings (Sociology:2018) list to record data on the leading sociology departments (see "Appendix 1" for the complete list of departments). After obtaining the list, several trained coders collected data from the official sites of the departments. There are several world university rankings with slightly different methodologies (Aguillo et al. 2010), the most famous among these the Academic Rankings of World Universities (ARWU), the QS ranking and the Times Higher Education ranking (THE). We have chosen the QS ranking for two main reasons. First, the ARWU was excluded because, in contrast to the QS and THE, it uses the Web of Science SSCI list for measuring publication output that is significantly more biased in social sciences than the more inclusive Scopus list used by 
both THE and QS (Demeter 2019a). From the two latter rankings, we chose QS because it is slightly more popular and established than the THE ranking (Alexa 2020). However, after we made a calculation regarding the similarities of the two respective lists, we found that they contained the same universities in their top 100 rankings to a factor of almost $75 \%$. Moreover, the geopolitical diversity of their top 100 university lists was almost identical, since both rankings contain mostly American, British, Western European and a few Asian universities, and, as a consequence, we can hypothesize that our calculations would be rather similar if we used the THE list instead of QS. Still, using solely the QS ranking could be conceived as a limitation of our analysis that could be extended with other rankings in future research.

According to our protocol, we collected data for only permanent faculty members and did not consider guest lecturers, externally funded researchers, and adjunct professors because they do not belong to the core faculty. We thought that the intellectual, cultural and ideological performance of a department is manifested, mostly, through its core faculty members who disseminate knowledge, academic culture and ideology permanently, while adjuncts, guests and externally funded researchers represent the main values of a department in a much smaller extent.

We recorded data on the academic staff members regarding the following features: gender (male/female), academic position (we will discuss it in detail below) and the places from which they have received their degrees (on BA, MA, and Ph.D. levels).

The academic position with which we measured academic stratification was categorized into three classes. The first class (1st position) consists of entrant positions like a researcher, assistant professor, and lecturer. The second class (2nd position) entails senior lecturers, senior researchers, readers and associate professors. Finally, the third and highest category (3rd position) consists of full professors.

After the data collection, we have a database of 3325 core staff members from the top 100 departments of sociology. Then we made several measurements in order to contrast empirical data with our hypotheses.

First, we measured the male/female ratio in our sample in every level of hierarchy: we calculated the ratio for the first, second and third positions and we investigated if there are differences between male/female ratios in different academic positions. We also measured the distribution of different academic positions.

Then we made calculations regarding the accumulated academic capital (in the form of university degrees) of the analyzed staff members. We investigated regional and mobility aspects by calculating the following features: the amount of core staff members who received their BA/MA/Ph.D. degrees from the same department they work in currently; from the same country; from the global North or the global South. We calculated this composition for every academic position (from 1 to 3 ) and for every university ranking positions (from 1 to 100). For coding the world regions, we used Demeter's categorization throughout (2018a).

We also made measurements regarding a form of transnational academic capital (Gerhards et al. 2017). By saying a form of transnational educational capital we mean the capacity of a country to export its academic capital in a way that its degrees are accepted and valued in other countries. We calculated transnational educational capital through the number of accepted degrees in different countries. Thus, for example, when we have a core staff member in a German sociology department with an American Ph.D. then it raises the value of the American Ph.D., and this counts as American transnational educational capital. Therefore, to value and accept a degree means no de jure but de facto acceptation that is manifested by how a scholar has been recruited with her degree from a given country. 
We also coded the total number of BA, MA and Ph.D. degrees from different countries. Thus the fact that there are three Canadian Ph.Ds in our sample means that there are three core faculty members on the list of the 3325 top-100 sociology department academics who received their Ph.D. degrees in Canada.

Finally, we calculated the career path network of the analyzed academics. In this phase, we used a more developed method that has been proposed by Clauset et al. (2015). In their analysis, a faculty member was represented as an $f=\langle u, v>$ directed edge that means $f$ has received her degree from $u$ and is currently working at $v$ (where both $u$ and $v$ refers to countries). Since we wanted to perform a more sophisticated analysis of the career paths, we measured BA, MA, and Ph.D. shifts, so a career path consists of a $w=<p, q, r, s>$ walk where $p$ is the country of the BA degree, $q$ is the country of the MA degree, $r$ is the country of the Ph.D. and $s$ is the country of current affiliation. For a more clear-cut representation, we also coded the variables delineated above by country, world region and global North—global South dichotomy (Demeter 2018a). We used Gephi analytic and visualization software throughout the analysis.

\section{Results}

The gender distribution of leading global sociology—which means the community of the top one-hundred sociology departments-shows a rather complex picture (see Fig. 1). If we consider the sum of the results, we can see that the proportion of male scholars slightly exceeds the proportion of female staff members in most departments. The overall proportions are $55 \%$ for male and $45 \%$ for female scholars in the total sample which includes all staff members. There are 26 departments with female staff member dominance while 74 departments have more male than female associates.

Moreover, if we consider different academic positions, an even more biased picture emerges. In the case of the first position which includes entry-level academics like lecturers and assistant professors, a significant female dominance could be seen. The proportions are the opposite of those demonstrated in the total sample, as in the first position the

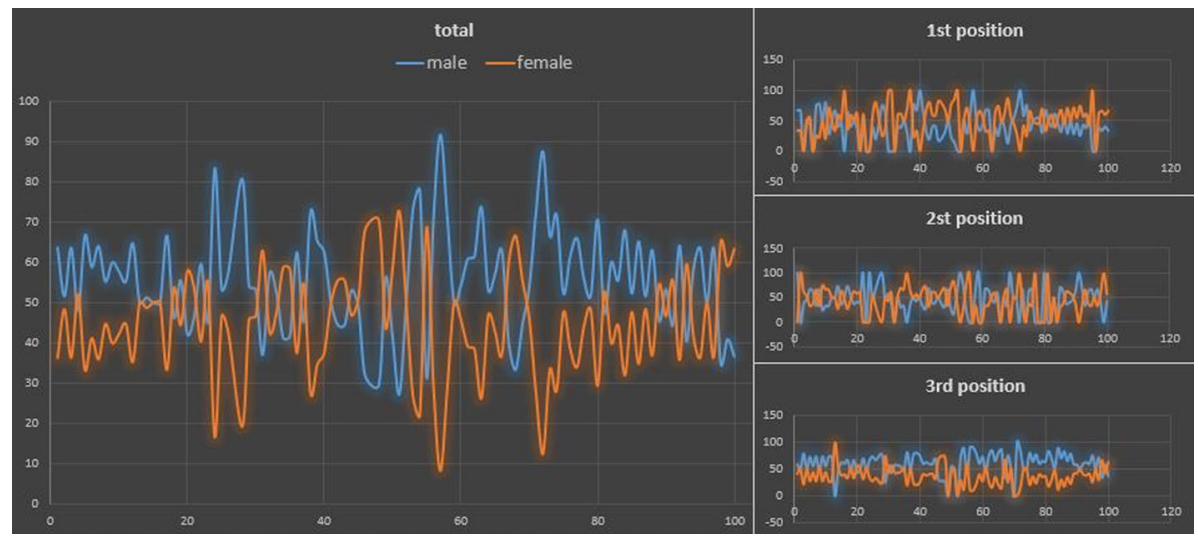

Fig. 1 Gender distribution in different academic positions. The vertical axis represents the proportion of male and female staff members in percentages while the horizontal axis shows department positions on the QS list (from 1 to 100) 
proportions are $55 \%$ for female staff members and $45 \%$ for male staff members. There are only 22 departments among the 100 where the number of male assistant professors and lecturers exceeds the number of their female peers. In the case of the next position (position 2 with associate professors, senior lecturers, and readers) we can see an almost balanced picture with slightly more (51\%) male employees. Finally, the most biased picture could be found regarding the most prestigious positions, namely in the case of university professors. Here we can see a significant male dominance where the amount of male professors is $64 \%$ against $36 \%$ of female academics in the same rank. There were only 14 institutions from the top 100 sociology departments with female dominance in the 3rd position. However, there were no significant correlations between department position and gender bias: at $p<0.05$ the values of $r$ were -0.1455 for the total sample, 0.3229 for the first, -0.1309 for the second and -0.2337 for the third position. These results could mean that these inequality patterns might be universal and they do not change with the departments' position in global university rankings. We will argue later that this significant gender inequality could be interpreted at least two rather different ways.

Figure 2 below represents the distribution of different academic positions. We can see that the most typical position is the third one. The average amount of professors is $44 \%$, followed by assistant professors and lecturers (30\%) and, finally associate professors, senior lecturers and readers have a share of $23 \%$ only.

The correlation between department positions and academic rank distribution is weak, with $p<0.05, r=0.3308$ for the first, $r=-0.0638$ for the second and $r=-0.2626$ for the third position. Despite these correlations being weak, their values for positions 1 and 3 could mean that the more prestigious a sociology department is, the more likely it has more full professors and less assistant professors.

We also calculated the male/female ratios for different world regions since it can be hypothesized that regional culture might have an effect on the gender distribution of the academic staff. As Fig. 3 shows, male dominance is most significant in both developing and developed Asian countries, followed by Western Europe where the proportion of male academics in the staff is still 60\%. Academic staffs in Anglo-Saxon and Scandinavian countries are much more balanced in terms of the proportion of female and male academics: Anglo-Saxon countries have a slight male dominance while their Scandinavian counterparts present a small female overrepresentation.

The distribution of the places from which our analyzed faculty members have their degrees shows that even those very few scholars from the periphery strive to get degrees

Fig. 2 The distribution of the three academic positions at the top 100 sociology department

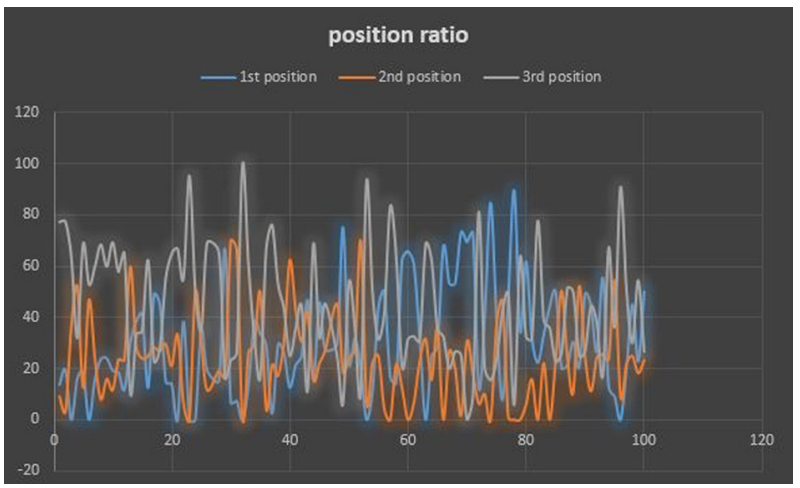


Fig. 3 The proportion of male/ female academic staff members by world regions



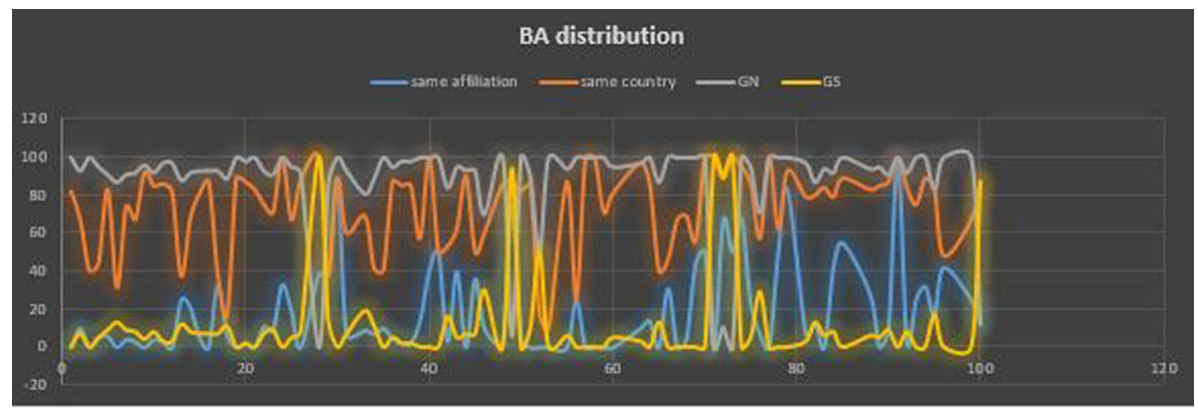


Fig. 4 The stratified distribution of BA, MA, and Ph.D. degrees 
from the global North as early as they can (Fig. 4). While there is a very limited but still measurable proportion of global South BA owners (an average of 11\%), this amount declines with MAs (5\%) and almost vanishes at Ph.D. level (3\%). However, as it will be demonstrated in the discussion section, even this minimal contribution comes from departments of the global South (from China, Brazil, and Russia), and there are literally no fully global South-educated academics at central (global North) departments. The consequences will be discussed later. We could also see that while recruiting academics from the same affiliation (18\% average) and from the same country (73\% average) is almost as frequent in the case of BA, MA and Ph.D. degrees, there is a tendency by which the most prestigious departments do not frequently employ their former students. On the other hand, less elite departments, especially those from the global South, are more likely to recruit their alumni.

When we take a look at the regional distribution of BA, MA and Ph.D. degrees, we see that top sociology departments are far from being diverse in terms of the education of their core staff members (Fig. 5).

As demonstrated, American degrees dominate the field over 50\% at every educational level, and there is only one global South country, namely China, that could participate in the club of top-10 educators at a BA level. However, at MA and Ph.D. levels there are no global South educators at all. The overall participation of the global South declines to only $1 \%$ at a Ph.D. level, but as we have mentioned earlier, this is due to the slight presence of global South departments on the list, as central departments seem to be unwilling to accept global South knowledge. Moreover, even if we have many Western countries in the sample, the US, the UK and Germany give more than three-fourths of these degrees at every level of higher education.

We can see the most unbalanced picture when we look at the global distribution of transnational educational capital (Fig. 6). The leading country, the US, has five times as much transnational educational capital than its runner-up, the UK, and despite the still limited

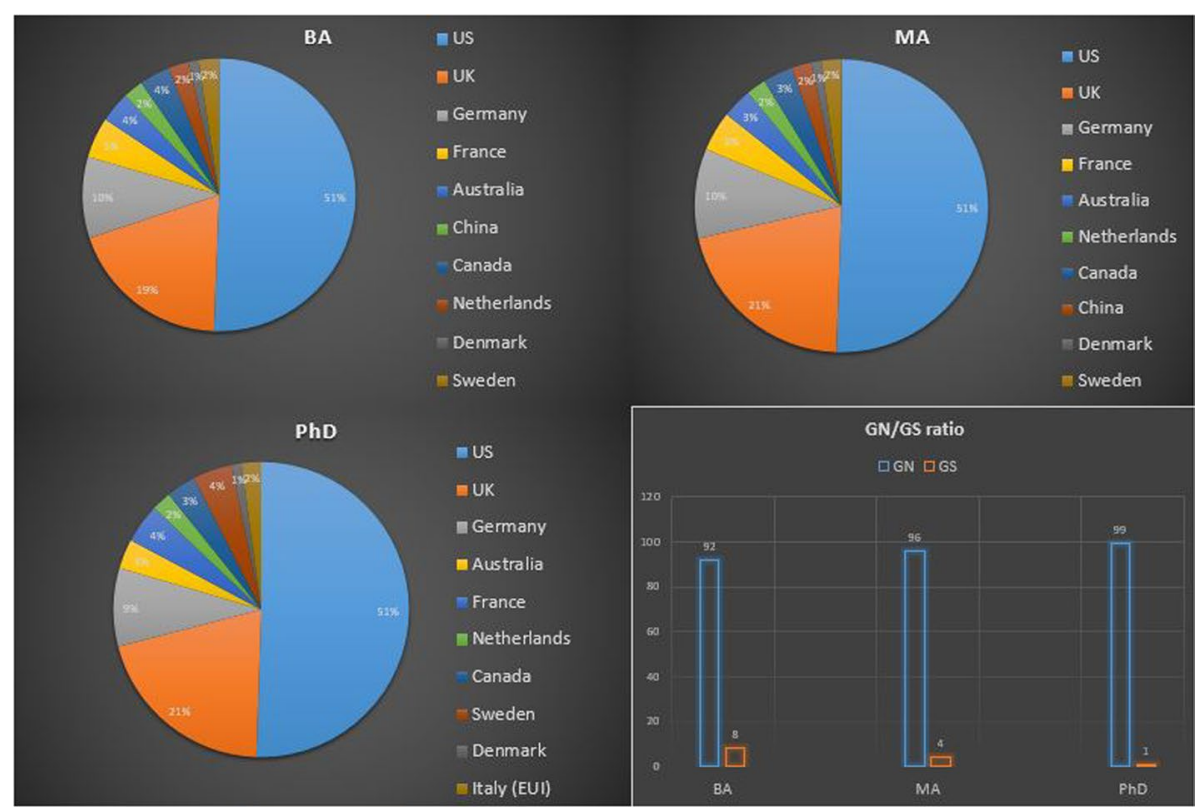

Fig. 5 The regional distribution of the top 10 most frequent BA, MA, and Ph.D. degrees 
Fig. 6 The regional distribution of transnational educational capital. The vertical axis represents the number of Ph.D. degrees accepted in countries other than the place of education

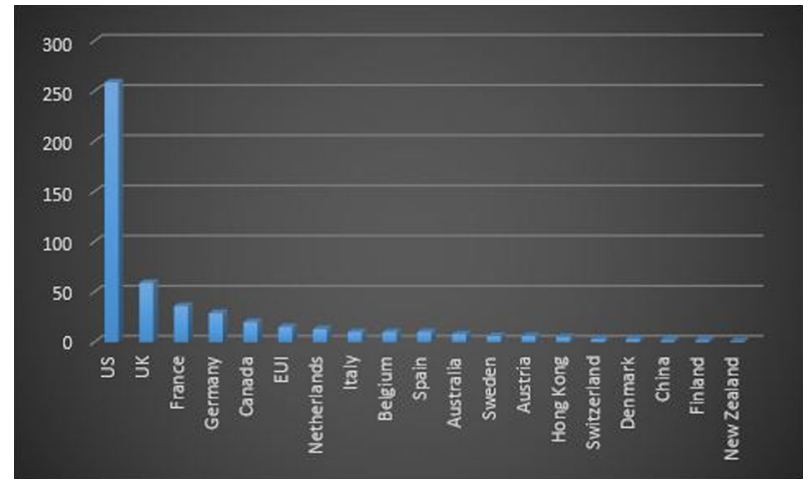

participation of France, Germany, and to an even smaller extent Canada, the Netherlands, and Italy (with the European University Institute), there are no more significant educational fund-holder countries. It is also clear from the picture that no countries from the global South succeeded in having transnational educational capital. This fact also shows that even the limited participation of global South education remains at home in the sense that global South educated academics, as opposed to their central peers, are most likely to be recruited by universities of their countries of origin.

Finally, our measurements of career paths in global sociology not only reinforce but also refine the picture that has already been evolving from our results (Figs. 7, 8, 9). The graphs have been designed in a way that the color along the edges represents the terminal points of the career paths, a blue edge meaning an education trajectory towards a country or region represented in blue.

The graph shows that while a career path towards a central global North country, and most typically to the US, the UK and Germany is an incredibly popular way for collecting educational capital, the opposite direction is without precedent. Still, we have some red lines meaning that global South institutions tend to accept the limited form of transnational educational capital and they might appreciate the degrees of each other. We will discuss this phenomenon later in details. Another figure shows the career paths by leading world regions (Fig. 8).

It is clear that, again, the United States is the main hub of transnational educational capital in the world with Canada, and while the UK is the second most powerful agent in this field, there are many emerging Western European hubs with almost equal power. Figure 9 shows a detail of the most powerful hubs of the network.

\section{Discussion and conclusions}

If we wanted a one-sentence answer to the question of what constitutes knowledge in global leading sociology, we would say that it is American and Western European knowledge, which could be collected at leading American and Western European universities. As a consequence, peripheral scholars that strive for an international career should go to the West for education. In consequence of a lack of data, we did not make measurements regarding the country of origin of the analyzed researchers, however it is reasonable to suppose that those scholars that gained their BA degrees in peripheral countries (and then 


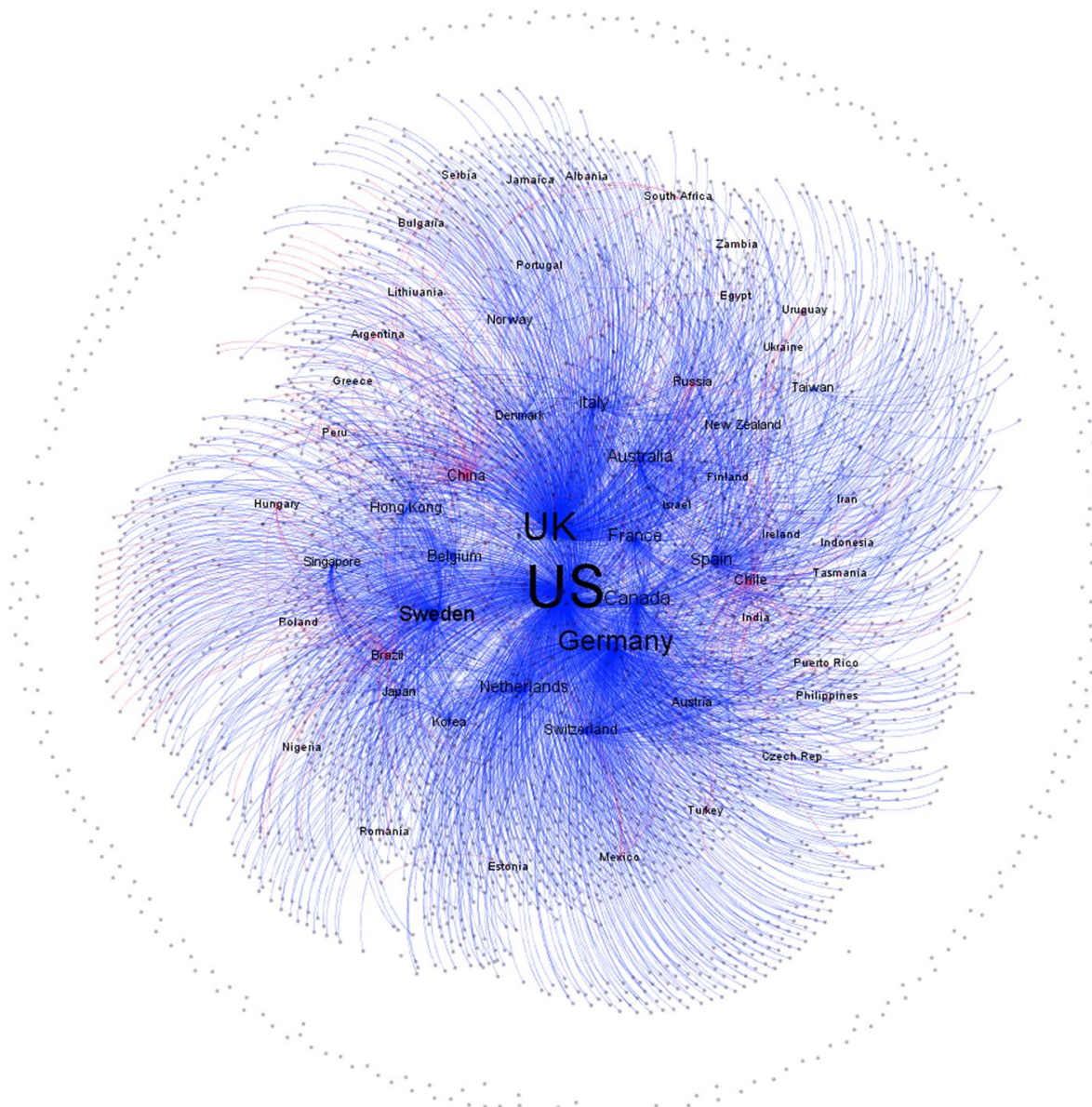

Fig. 7 Career paths of sociology scholars of elite departments. Blue dots represent global North institutions while red ones refer to their global South counterparts. (Color figure online)

went to the West for their MA and Ph.D. degrees) originated in the country of their BAs. It is not plausible to suppose that a scholar who was born in the West would go to the periphery to get his or her BA, and then go back to the West. It is more plausible to suppose that a peripheral BA — central MA — central Ph.D. trajectory refers to a scholar that originates at the periphery and then goes to the West.

Our analysis regarding the vertical dimension of the core-periphery structure of the world-system of elite global sociological scholarship has been restricted to only one peripheral subgroup of the society, namely women. Our selection criterion was established due to the fact that this is the most populous subgroup in society that has its members in all classes and world regions. Moreover, as not only classical sociologists of science like Bourdieu and world-systems analysts like Wallerstein, but also current researchers have put it, women are oppressed in all areas of science. The phenomenon called the Matilda-Effect (Knobloch-Westerwick et al. 2013) is the counterpart of the infamous Matthew-Effect in Science (Merton 1968) where the latter refers to the serious bias against peripheral 


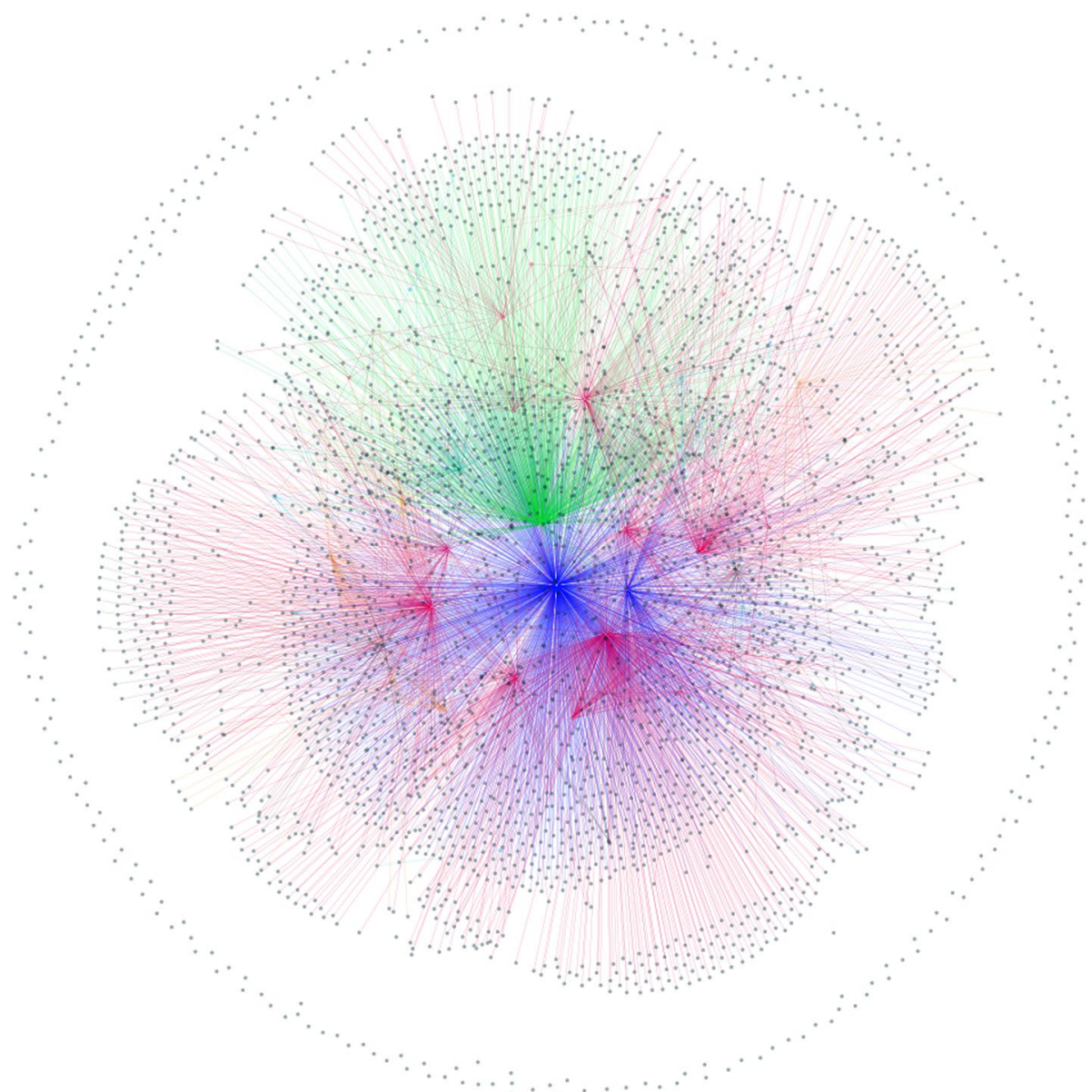

Fig. 8 Main centers and world regions. Blue: North America. Red: Western Europe. Green: The United Kingdom. (Color figure online)

scientists while the former refers to the undervaluation of women in the academy. Nevertheless, we might suppose that at least in sociology, that is, in the discipline where the underrepresentation of women in top positions in general, and in the global academy in particular, is a frequently criticized phenomenon, we would find a more balanced picture. However, our analysis shows that difference between the participation of female and male academics was $10 \%$ in favor of men, but the picture is much more complex, as the differences vary by world regions and in every stage of academic promotion. Regarding world regions, we found that regional culture has a significant impact on the gender diversity of academic staff members, and as a consequence, Anglo-Saxon and European universities are much more balanced in this respect than their Asian counterparts.

When we assess the world-system of leading sociology, the vertical axis of our model shows a typical stratification pattern where the dominant group occupies top positions while the members of the disadvantaged group take the lower positions. Stratification is also obvious due to the fact that the amount of participation from the hegemon group 


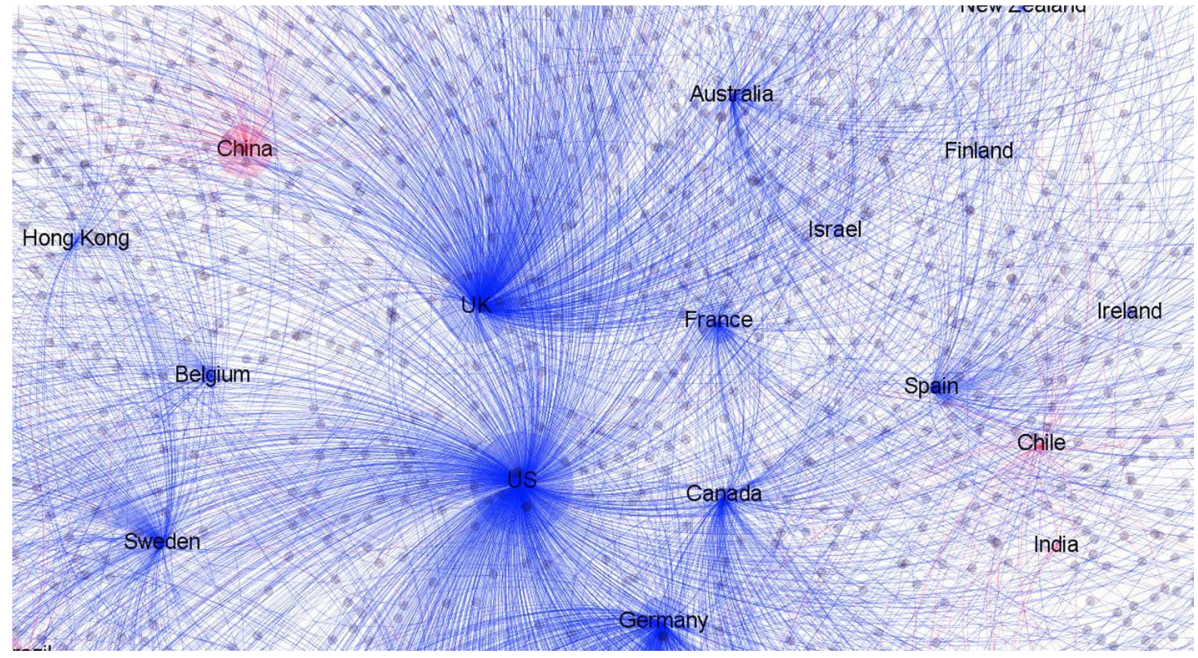

Fig. 9 The dominant center of global sociology — detail

rises in every stage of an academic career: the most biased picture could be found on the top level, while the participation of the disadvantaged group is greater in every level downwards. In order to interpret these findings we could construct different conditional explanations.

The first potential explanation could be that the system of global sociology might prohibit the progress of female academics. One could say, however, that maybe fewer women wanted to be a full professor, but this explanation contradicts the fact that there are more female academics in the first position which means that, actually, more women choose to work as a scholar in sociology compared to men. We could not reasonably suppose that they want to remain on the first level as assistant professors; instead, we should assume that in some stage of their career trajectories they are systematically blocked. This explanation should assume the so-called glass ceiling which prohibits or at least embarrasses women trying to reach top positions. Our results also show that, if the glass ceiling exists, it is related to the culture of a given society, and most likely it is these societies which maintain the so-called traditional roles for women, as Asian countries would produce more barriers to the academic development of female scholars by making them disproportionally involved in housework or bringing up children.

However, an alternative explanation could presume that, since academic discrimination against women was more extensive before, the differences between male/female ratios are based on age group differences. Thus, the lower representation of female scholars on the level of professors could be explained by the fact that professors are, on average, older than assistant professors, and that the bias was stronger in the time they were appointed. This explanation presupposes that the gender diversity on the top level will be more balanced in the long run when current assistant professors will be appointed as full professors. Future studies will show if the current gender composition of the assistant professor cluster will modify in time, and this will presumably decide if the glass-ceiling interpretation or the historical interpretation offer a more adequate explanation of the gender inequalities at different academic positions as experienced today. 
Turning now to the geographical core-periphery structures, we can see that the distribution of global knowledge as it is represented by the degrees of the top sociology departments' staff is neither diverse nor international. More than half of the degrees originate in the US at both graduate and postgraduate levels, and the global north's participation in this respect goes from 89 to $97 \%$. We have to emphasize that this US dominance in academic degrees (a 52\% average) could not be simply explained by the great number of US departments $(27 \%)$ or members at US departments (40\%) in the sample. As it will be discussed later, the US as the super central agent of the world-system of global sociology is a net exporter in the sense that US degrees are overrepresented in not just American but in other central and, as we will see later, even peripheral departments. On the other hand, peripheral countries are net importers in the sense that it is not just that their degrees are not accepted elsewhere in the world but that they also import global North, typically American academic degrees. As opposed with peripheral countries, the US does not really import knowledge, as the number of American staff members with doctorates from outside the US is only $3 \%$.

While it is obvious that the US is the main knowledge exporter in global sociology, and North American certifications are welcomed all around the world, the situation is more complicated in the case of other countries. The first type to analyze is the case of the UK, which is the second most successful country in terms of knowledge export. UK elite universities prefer UK education since most staff members have degrees from local universities, but there are numerous cases where they employ staff educated outside the country $(23 \%)$. However, these degrees cannot be from any country: they are limited to the U.S. and Western Europe. Notwithstanding, regional plurality is much stronger in the UK than in the U.S. If we consider the top 10 departments only, with seven US and three UK departments, we can see that the amount of imported knowledge is relatively high (45\%) at British institutions, while almost zero (2\%) in the case of US departments. Moreover, we should add that in the case of the UK, $76 \%$ of the degrees accepted from outside the UK are from the US. Thus, naming the US as the hegemon supercenter of global sociology is not a hyperbolism, as this is the country where one cannot have an elite academic position without US (re)education, and its intellectual colonialism covers not only the developing countries, but also reaches other developed core countries like the UK.

Another characteristic group consists of relatively powerful but traditionally nationalist and less internationalized countries like France and Germany. Their internationalization strategies are quite different from that of the US and the UK since neither Germany nor France are interested in knowledge export and import. The amount of staff members with a national Ph.D. is $92.5 \%$ in the case of France, and $84 \%$ in Germany. The same is true to a less significant extent regarding elite departments in smaller Western European countries like the Netherlands, Sweden, Finland, Norway, Austria, and Belgium. The most nationalist country in this sense, or rather the most closed to outside knowledge is Japan, where the full staff at the University of Tokyo have Japanese postgraduate educations and are therefore likely to disseminate local knowledge.

From a world-systemic perspective it is important to analyze those departments that could be called institutions of knowledge colonialism. We can find them all over the world: from Asia through Eastern Europe to Latin-America. These institutions represent central knowledge almost exclusively, as in the case of the partly American Central European University in Hungary (CEU). Amongst the sociology staff members of CEU, there is no one with a Hungarian (or other Eastern European) Ph.D. while all staff members have global North, typically American educations (60\%). Consequently, it is rather questionable that CEU represents Central European knowledge at all, rather one could only expect to learn 
mainstream Western knowledge. In other words, while CEU and similar American universities located at the periphery produce knowledge that is generally added to the scientific output of the host country, these institutions do not accept local knowledge manifested by local degrees, since they typically do not employ locally-educated staff members. This phenomenon could be interpreted at least two ways. According to the first interpretation, the content of peripheral education is considered questionable by these institutions, while the second interpretation supposes that, while its content is appropriate, the quality of peripheral education is inferior to Western education. From a world-systemic point of view, both of the above interpretations represent Western ethnocentrism and knowledge imperialism since they presuppose that host countries at the periphery are not capable of providing appropriate knowledge, and therefore it should be imported from the West.

Other typical knowledge colonies in our sample are the sociology departments of developed Asian countries like Singapore, Hong Kong, and South Korea. According to our data, one could hardly get an occupation in these countries at an elite sociology department without being re-educated at the global North, again, typically in the US. The amount of central education present at the level of Ph.D. is 75\% at Korea University, 95\% at the National University of Singapore, 78\% at the University of Hong Kong, 64\% at Seoul National University and $93 \%$ at the Chinese University of Hong Kong. On the other side of the ocean, we have Chile as a typical knowledge-colonized country since staff members with central education dominate at both Pontificia Universidad Católica de Chile (100\%) and Universidad de Chile (79\%).

Finally, there are important bigger countries that could not be easily labeled by the categories delineated above, so we will discuss them individually. The first is Canada, a country with an internationally-recognized higher education as the fourth greatest knowledge exporter in the world. Notwithstanding, Canadian elite sociology departments prefer US education to their own, since most of their staff members are educated at their southern neighbor, or at other central countries like the UK or Germany. The amount of nonCanadian knowledge dominance varies from the 57\% of Queens University to the $91 \%$ of McGill, while the most prestigious department in Canadian sociology, namely, the sociology department of the University of Toronto, has $85 \%$ staff members with a Ph.D. outside of Canada, from which $81 \%$ have a US doctoral degree. Next we have Australia which, similarly to Canada, has many internationally-ranked top 100 sociology departments, however as opposed to Canada, it does not depend on an enormous knowledge import. The amount of imported foreign knowledge in Australian departments ranges from only 13\% at Monash University to $67 \%$ at the University of Melbourne, therefore while knowledgeexport from the center is also an important issue in Australia, the extent of local knowledge used is far more considerable than that in Canada. Finally, we have two-three large empires from the global South: China, Russia, and Brazil. In the case of these empires, we can see that they equally accept local knowledge and import central knowledge while they are both unable to export their local science, as there are almost no academics outside China and Russia with Chinese or Russian PhDs at elite departments. Nevertheless, as opposed to knowledge-colonized Asian countries such as Singapore or Korea, local knowledge is appreciated since there are many staff members at elite Chinese and Russian sociology departments with a fully local education. The same could be said in Brazil where the amount of locally-educated staff members is $90 \%$.

When we take a look at career trajectories in the world-system of elite sociology we will see both centripetal and centrifugal forces. By centripetal forces, we mean that in order to be internationally recognized and recruited by an elite sociology department, peripheral scholars have to subject themselves to central reeducation. It means that the so-called 
international sociology does not respect local or peripheral knowledge, but only central, most typically Anglo-American knowledge, while systematically excluding those scholars without central educational capital. Our research shows that while $11 \%$ of the research staff of all the analyzed departments started their higher education at peripheral institutions, they most likely originated from the country of their BAs, and this proportion fell to $5 \%$ on the MA level, and to 3\% on the Ph.D. level. From this data, we could see that an excessive brain drain and reeducation happens in the world-system of global sociology where local or peripheral candidates should be formed on the model of their central peers. On the other hand, centrifugal forces mean that those scholars who would not subject themselves to central reeducation will be excluded from elite institutions. Our findings reveal that knowledge exchange seems to be one-directional: while central knowledge is appreciated and, especially in the knowledge colonies, overvalued on the periphery, peripheral knowledge is absolutely depreciated at the center. In our sample of more than 3000 scholars working at central deparments, there was no one with a peripheral postgraduate education, despite the fact that slightly more than $10 \%$ of the sample have a peripheral undergraduate education history.

\section{Addressing our hypotheses}

Our first hypothesis said that in terms of academic capital (measured in university degrees), the field of global sociology is strongly stratified and only slightly international. This hypothesis was corroborated by our data: the top hundred sociology departments have almost exclusively core staff members with central education, and in order to be recruited, peripheral scholars must be re-educated at the center. Internationality levels are relatively low in both graduate and postgraduate levels since the amount of staff members educated in the same country as the institution is over $70 \%$ in the case of all analyzed levels of higher education from BA to $\mathrm{Ph}$.D. The analyzed departments are also stratified vertically: we found that women are underrepresented globally by $10 \%$, and their participation at top positions is weaker by $30 \%$ than their male peers.

The second hypothesis suggests that the process of brain drain is at work within the field so that the internationalization level decreases from BA to Ph.D. degrees. Our research shows that peripheral education decreases from $11 \%$ at BA level to 5\% at MA, and to 3\% at the Ph.D. level. But this hypothesis was only partly corroborated since general international levels did not fall from BA to Ph.D. While the share of the periphery drastically declines on higher levels, the positions are refilled with central international agents so the amount of international education remains the same, only the share of the periphery falls drastically.

Our third hypothesis states that the picture of global sociology shows a center-periphery structure in terms of both the participation of peripheral groups and the accumulated academic capital. This hypothesis has been also corroborated. The center-periphery structure (Figs. $7,8,9$ ) could be represented by not only the fact that amongst the 3325 core staff members of the top 100 sociology departments there are only $11 \%$ who presumably originated at the periphery, while reeducation trajectories also show that even from this $11 \%$ there are only $3 \%$ with peripheral postgraduate education. And even this $3 \%$ works, without exceptions, at peripheral departments.

Finally, our fourth hypothesis suggests that some intermediates would emerge and constitute the semi-periphery of the field of global sociology. Our research shows that the world-system of sociology has a complex structure with horizontal segmentation and 


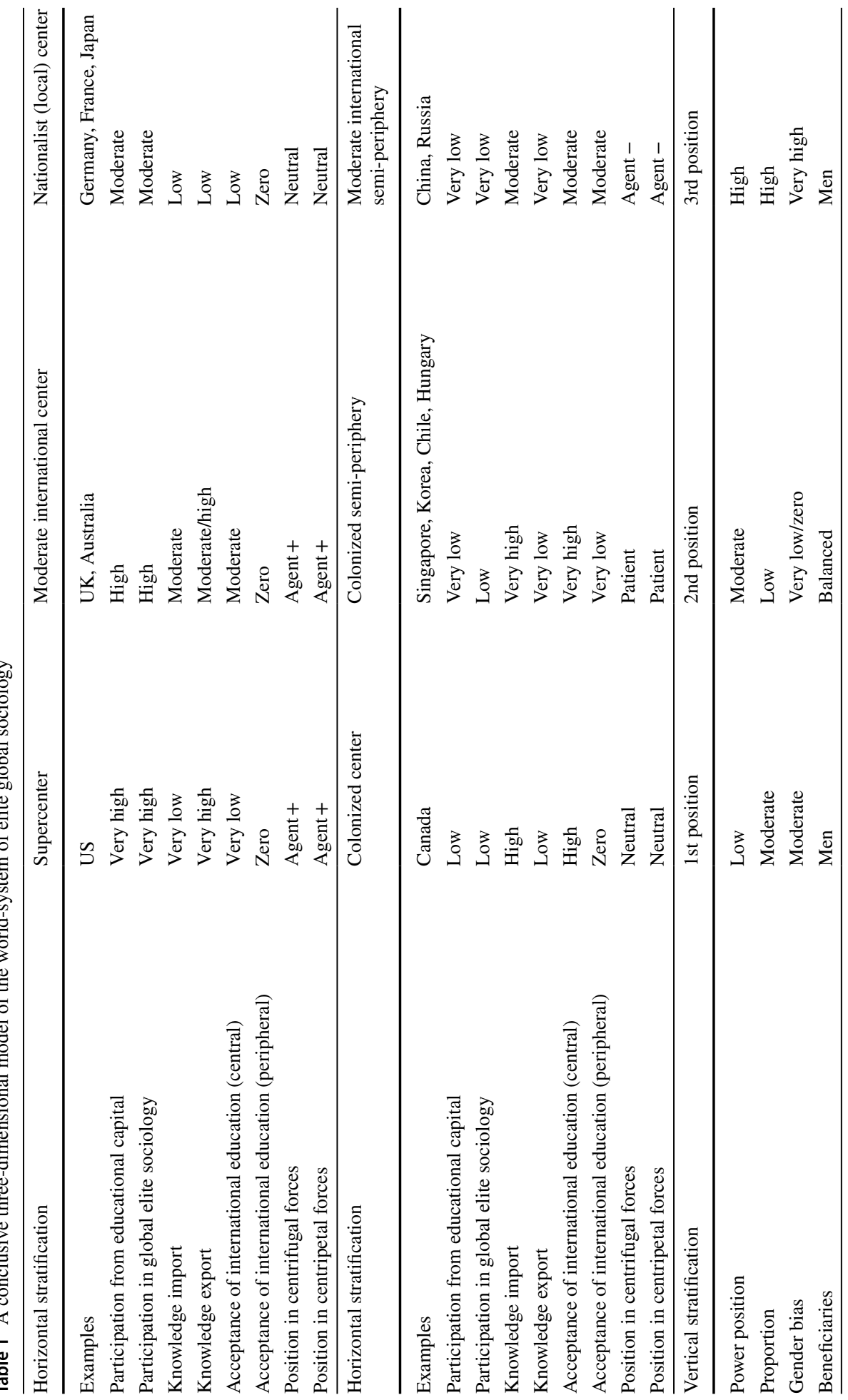




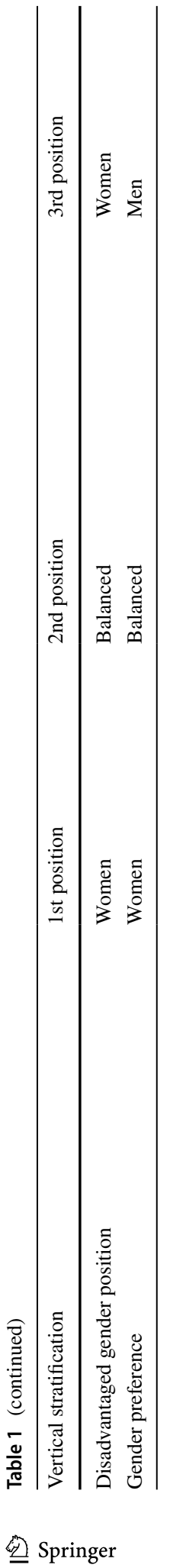


vertical stratification. Table 1 summarizes the main features of the world-system of current elite sociology in terms of both its horizontal and vertical stratification.

In order to avoid an oversimplified picture of a centrally-controlled academic field, we have to consider the varieties different world regions developed in order to operate in the world-system of global sociology. Between the super central US and the super peripheral and thus invisible regions of the periphery, there are a considerable number of variations. Moderate international centers like the UK and Australia are centers in their own right: they don't need foreign knowledge, but as opposed to the US, they also don't refuse it, at least while it comes from the Western world. But since both the supercenter and these moderate international centers attract and reeducate foreign human resource while excluding those without Western education, they positively influence both the centripetal and the centrifugal forces of the world-system. On the other hand, local centers like France, Germany or Japan do not have a significant effect on these above mentioned world-systemic dynamics since they neither export nor import extensive international knowledge, while all of them appreciate their national education. The opposite could be stated on colonized centers like Canada that do not value their own education system and rest on extensive knowledge import. Semi-peripheral countries with colonized knowledge such as Singapore, Hungary or Chile are net knowledge importers to a greater extent than colonized centers: in many instances, colonized semi-peripheral departments run without any nationally-educated staff members. In this way, they are participating in the world-systemic dynamics of global elite sociology as the patients or endurers of centripetal and centrifugal operation. Finally, we have the moderate international semiperiphery, the sole regions of the world-system that could stand against the centripetal and centrifugal operation of the system. In huge and populated countries like China, Russia, and Brazil, local departments not just tolerate but even appreciate local knowledge and even foreign knowledge from the global South.

\section{Limitations}

The most considerable limitation of this present study relates to the measurement of academic stratification that deals only one aspect of social stratification, namely gender. Further analyses should extend the scope of academic stratification with other aspects such as wealth, education an family background, race and so on.

Moreover, due to the focus of this research, we could not deal with a very important feature of the global academy and in particular of global sociology: its within-center stratification, meaning that there are central (elite) and peripheral (mass education) institutions within the same country. Therefore, on the next level of our analysis, we will have to deal with institutional central-periphery relations, and that picture would modulate our understanding of the world-system of elite sociology.

Finally, we were not able to measure the scientific output of the analyzed scholars in this research, since we concentrated here on career trajectories and accumulating academic capital by education. However, the center-peripheral bias in knowledge production is an extensively investigated field of research, and in almost every case, researchers found a significant overrepresentation of Western topics and Western authors in leading international journals that are in the hands of Western publishing houses (Altbach 2010; Canagarajah 2002; Lauf 2005). In our opinion, it would be an unneeded simplification to say that scholars with central degrees have better training and, consequently, perform better than their peripheral peers, thus they should take the top positions at global academy. Current research has even found that Western education does not enhance, but on the contrary 
slightly decreases the research performance of the most productive scholars at the global South (Demeter 2019b). Nevertheless, future research should investigate the proportion in which staff members at leading departments accumulate their academic capital in terms of both elite degrees and publication output.

Acknowledgements Open access funding provided by National University of Public Service.

Funding This study was supported by the Bolyai Fellowship of the Hungarian Academy of Sciences.

Open Access This article is licensed under a Creative Commons Attribution 4.0 International License, which permits use, sharing, adaptation, distribution and reproduction in any medium or format, as long as you give appropriate credit to the original author(s) and the source, provide a link to the Creative Commons licence, and indicate if changes were made. The images or other third party material in this article are included in the article's Creative Commons licence, unless indicated otherwise in a credit line to the material. If material is not included in the article's Creative Commons licence and your intended use is not permitted by statutory regulation or exceeds the permitted use, you will need to obtain permission directly from the copyright holder. To view a copy of this licence, visit http://creativecommons.org/licenses/by/4.0/.

\section{Appendix 1}

Sociology departments involved in the analysis

\begin{tabular}{lll}
\hline QS World University & University (Department of Sociology) & Country \\
\hline 1 & & \\
2 & Harvard University & US \\
3 & University of California, Berkeley & US \\
4 & University of Oxford & UK \\
5 & London School of Economics and Political Science & UK \\
6 & Stanford University & US \\
7 & University of Cambridge & UK \\
8 & University of Chicago & US \\
9 & University of California, Los Angeles & US \\
10 & Yale University & US \\
11 & Princeton University & US \\
12 & Columbia University & US \\
13 & University of Wisconsin-Madison & US \\
14 & Australian National University & Australia \\
15 & University of Amsterdam & Netherlands \\
16 & University of Michigan & US \\
17 & New York University & US \\
18 & National University of Singapore & Singapore \\
19 & University of Toronto & Canada \\
20 & Cornell University & US \\
21 & University of Manchester & UK \\
22 & MIT & US \\
23 & Freie Universitaet Berlin & Germany \\
24 & Humboldt Universitat zu Berlin & Germany \\
\hline & University of Tokyo & Japan \\
\hline
\end{tabular}




\begin{tabular}{|c|c|c|}
\hline $\begin{array}{l}\text { QS World University } \\
\text { Position }\end{array}$ & University (Department of Sociology) & Country \\
\hline$\overline{25}$ & University of Edinburgh & UK \\
\hline 26 & University of North Carolina, Chapel Hill & US \\
\hline 28 & Peking University & China \\
\hline 29 & University of Hong Kong & Hong Kong \\
\hline 30 & University of Copenhagen & Denmark \\
\hline 31 & University of Sydney & Australia \\
\hline 32 & Seoul National University & South Korea \\
\hline 33 & University of Texas at Austin & US \\
\hline 34 & University of British Columbia & Canada \\
\hline 35 & University of Melbourne & Australia \\
\hline 36 & Brown University & US \\
\hline 37 & City University of New York & US \\
\hline 38 & Sciences Pro & France \\
\hline 39 & McGill University & Canada \\
\hline 40 & Monash University & Australia \\
\hline 41 & The Chinese University of Hong Kong & Hong Kong \\
\hline 42 & University of Essex & UK \\
\hline 43 & University of Queensland & Australia \\
\hline 44 & Duke University & US \\
\hline 45 & University of Stockholm & Sweden \\
\hline 46 & Lancaster University & UK \\
\hline 48 & Goldsmiths University of London & UK \\
\hline 49 & Pontificia Universidad Catolica de Chile & Chile \\
\hline $50-100$ & University of Warwick & UK \\
\hline $50-100$ & Boston University & US \\
\hline $50-100$ & Central European University & Hungary \\
\hline $50-100$ & European University Institute & Italy \\
\hline $50-100$ & Johns Hopkins University & US \\
\hline $50-100$ & KU Leuven (BEL) & Belgium \\
\hline $50-100$ & Korea University & South Korea \\
\hline $50-100$ & Kyoto University & Japan \\
\hline $50-100$ & University Leiden & Netherlands \\
\hline $50-100$ & Ludwig-Maximilians-Universität München & Germany \\
\hline $50-100$ & Northwestern University & US \\
\hline $50-100$ & Queens University & Canada \\
\hline $50-100$ & SOAS University of London & UK \\
\hline $50-100$ & University of Auckland & New Zealand \\
\hline $50-100$ & UNSW Sydney & Australia \\
\hline $50-100$ & University of Sheffield & UK \\
\hline $50-100$ & University of Western Australia & Australia \\
\hline $50-100$ & Trinity College Dublin & Ireland \\
\hline $50-100$ & Tsinghua University & China \\
\hline $50-100$ & Universidad de Chile & Chile \\
\hline $50-100$ & Universidade de Sao Paulo & Brazil \\
\hline $50-100$ & University of Bologna & Italy \\
\hline
\end{tabular}




\begin{tabular}{lll}
\hline $\begin{array}{l}\text { QS World University } \\
\text { Position }\end{array}$ & University (Department of Sociology) & Country \\
\hline $50-100$ & University of Bielefeld & Germany \\
$50-100$ & Universität Frankfurt am Main & Germany \\
$50-100$ & Universität Mannheim & Germany \\
$50-100$ & University of Vienna & Austria \\
$50-100$ & University College London & UK \\
$50-100$ & University of Birmingham & UK \\
$50-100$ & University of Bristol & UK \\
$50-100$ & University of California, Irvine & US \\
$50-100$ & University of California, San Diego & US \\
$50-100$ & Universtiy of Gothenburg & Sweden \\
$50-100$ & University of Leeds & UK \\
$50-100$ & University of Maryland & US \\
$50-100$ & University of Notre Dame & US \\
$50-100$ & University of Oslo & Finland \\
$50-100$ & University of Pennsylvania & US \\
$50-100$ & University of Sussex & UK \\
$50-100$ & University of Washington & US \\
$50-100$ & University of Uppsala & Sweden \\
$50-100$ & University of Lausanne & Switzerland \\
$50-100$ & Sorbonne University & France \\
$50-100$ & National Research University Higher School of Economics & Russia \\
\hline & &
\end{tabular}

\section{References}

Aguillo, I., Bar-IIan, J., Levene, M., \& Ortega, J. (2010). Comparing University rankings. Scientometrics, $85(1), 243-256$.

Alexa. (2020). topuniversities.com. Competitive analysis, marketing mix and traffic. Retrieved from (https:// www.alexa.com/siteinfo/topuniversities.com. Accessed 13 June 2020.

Altbach, P. G. (2010). Preface. In G. Goastellec (Ed.), Understanding inequalities in, through and by higher education. Rotterdam: Sense Publishers.

Anderson, L. (2013). Publishing strategies of young, highly mobile academics: The question of language in the European context. Language Policy, 12, 273-288.

Baldi, S. (1994). Changes in the stratification structure of sociology: 1964-1992. American Sociologist, 25, $28-43$.

Ball, S. J., Reay, D., \& David, M. (2003). Ethnic choosing: Minority ethnic students, social class, and higher education choice. Race, Ethnicity, and Education, 5(4), 333-357.

Bennett, K. (2015). Towards an epistemological monoculture: Mechanisms of epistemicide in European research publication. In R. Plo Alastrué \& C. Pérez-Llantada (Eds.), English as a scientific and research language (pp. 9-36). Berlin: De Gruyter.

Boncourt, T. (2018). What "internationalization" means in the social sciences. A comparison of the international political science and sociology associations. In J. Heilbron, G. Sorá, \& T. Boncourt (Eds.), The social and human sciences in global power relations. Cham: Palgrave Macmillan.

Bonitz, M., Bruckner, E., \& Scharnhorst, A. (1997). Characteristics and impact of the Matthew effect for countries. Scientometrics, 40(3), 407-422.

Bourdieu, P. (1988). Homo academicus. Stanford: Stanford University Press.

Bourdieu, P. (1996). The state nobility. Elite schools in the field of power. Oxford: Polity Press. 
Burris, V. (2004). The academic caste system: Prestige hierarchies in Ph.D. exchange networks. American Sociological Review, 69(2), 239-264.

Canagarajah, S. A. (2002). A geopolitics of academic writing. Pittsburgh: University of Pittsburgh Press.

Clauset, A., Arbesman, S., \& Larremore, D. B. (2015). Systematic inequality and hierarchy in faculty hiring networks. Science Advances, 1(1), 1-6.

Cole, W. M. (2017). World polity or world society? Delineating the statist and societal dimensions of the global institutional system. International Sociology, 32(1), 86-104.

Collyer, F. (2014). Sociology, sociologists, and core-periphery reflections. Journal of Sociology, 50(3), 252-268.

Cowan, R., \& Rossello, G. (2018). Emergent structures in faculty hiring networks, and the effects of mobility on academic performance. Scientometrics, 117, 527-562.

Cret, B., \& Musselin, C. (2010). Academic hiring and Inequality. In G. Goastellec (Ed.), Understanding inequalities in, through and by higher education (pp. 75-90). Rotterdam: Sense Publishers.

Curry, M. J., \& Lillis, T. (2018). Global academic publishing. Policies, perspectives, and pedagogies. Bristol: Multilingual Matters.

de Sousa Santos, B. (2007). Cognitive justice in a global world: Prudent knowledges for a decent life. Lanham: Lexington.

de Sousa Santos, B. (2018). The end of the cognitive empire. The coming of age of epistemologies of the south. London: Duke University Press.

Demeter, M. (2017). The core-periphery problem in communication research: A network analysis of leading publication. Publishing Research Quarterly, 33(4), 402-421.

Demeter, M. (2018a). Nobody notices it? Qualitative inequalities of leading publications in communication and media studies research. International Journal of Communication, 12, 1001-1031.

Demeter, M. (2018b). Theorizing international inequalities in communication and media studies. A field theory approach. KOME: An International Journal of Pure Communication Inquiry, 6(2), 92-110.

Demeter, M. (2019a). Bung the gap: Narrowing Global North-Global South bias in measuring academic excellence by weighting with academic capital. KOME: An international Journal of Pure Communication Inquiry, 7(2), 1-16.

Demeter, M. (2019b). The winner takes it all: International inequality in communication and media studies today. Journalism and Mass Communication Quarterly, 96(1), 37-59.

Efranmanesh, M., Tahira, M., \& Abrizah, A. (2017). The publication success of 102 nations in scopus and the performance of their scopus-indexed journals. Publishing Research Quarterly, 33(4), 421-433.

Egron-Polak, E. (2012). Internationalization of higher education: A few global trends and regional perspectives. In C. Ennew \& D. Greenaway (Eds.), The globalization of higher education. New York: Palgrave Macmillan.

Enders, J. (2001). A chair system in transition: Appointments, promotions, and gate-keeping in German higher education. Higher Education, 41(1/2), 3-25.

Ennew, C., \& Greenaway, D. (2012). The globalization of higher education. New York: Palgrave Macmillan.

Fumasoli, T., Goastellec, G., \& Kehm, B. M. (2015). Academic work and careers in Europe: Trends, challenges, perspectives. New York: Springer.

Gerhards, J., Hans, S., \& Carlson, S. (2017). Social class and transnational human capital. How middle and upper-class parents prepare their children for globalization. London: Routledge.

Heilbron, J., Sorá, G., \& Boncourt, T. (2018). The social and human sciences in global power relations. Cham: Palgrave Macmillan.

Herschberg, C., Benschop, Y., \& van den Brink, M. (2018). Selecting early-career researchers: The influence of discourses of internationalisation and excellence on formal and applied selection criteria in academia. Higher Education (advance online publication).

Kerr, J. (2014). Western epistemic dominance and colonial structures: Considerations for thought and practice in programs of teacher education. Decolonization: Indigeneity, Education Society, 3(2), 83-104.

Knobloch-Westerwick, S., Glynn, C. J., \& Huge, M. (2013). The Matilda Effect in science communication: An experiment on gender bias in publication quality perceptions and collaboration interest. Science Communication, 35(5), 603-625.

Larson, J. (2018). Other voices: Authors' literary-academic presence and publication in the discursive world system. Discourse: Studies in the Cultural Politics of Education, 39(4), 521-535.

Lauf, E. (2005). National diversity of major international journals in the field of communication. Journal of Communication, 55(1), 129-151. 
Long, J. S. (1979). Productivity and academic position in the scientific career. American Sociological Review, 43, 889-908.

Long, J. S., Allison, P. D., \& McGinnis, R. (1979). Entrance into the academic career. American Sociological Review, 44(5), 816-830.

Mahroum, S. (2002). Highly skilled globetrotters: Mapping the international migration of human capital. $R \& D$ Management, 30(1), 23-31.

Maliniak, D., Peterson, S., Powers, R., \& Tierney, M. J. (2018). Is international relations a global discipline? Hegemony, insularity, and diversity in the field. Security Studies, 27(3), 448-484.

Marginson, S. (2007). Have global academic flows created a global labour market? In D. Epstein, R. Boden, R. Deem, F. Rizvi, \& S. Wright (Eds.), Geographies of knowledge, geometries of power: Framing the future of higher education (pp. 305-319). London: Routledge.

McDonough, P. M., \& Fann, A. J. (2007). The study of inequality. In P. Gumport (Ed.), Sociology of higher education. Contributions and their contexts (pp. 53-93). Baltimore: The John Hopkins University Press.

Merton, R. K. (1968). The Matthew effect in science. The reward and communication systems of science are considered. Science, 159, 56-63.

Meyer, J. W., Boli, J., Thomas, G. M., \& Ramirez, F. O. (1997). World society and the nation-state. American Journal of Sociology, 103(1), 144-181.

Meyer, J. M., Ramirez, F. O., \& Soysal, N. (1992). World expansion of mass education, 1870-1980. Sociology of Education, 65(2), 128-149.

Mignolo, W. D. (2011). The darker side of western modernity: Global futures, decolonial options. Durham: Duke University Press.

Mignolo, W. D. (2018). On decoloniality: Concepts, analytics, Praxis. North Carolina: Duke University Press.

Moody, J. (2004). The structure of a social science collaboration network: Disciplinary cohesion from 1963 to 1999. American Sociological Review, 69(2), 213-238.

Musselin, C. (2004). Towards a European Academic Labour Market? Some lessons drawn from empirical studies on academic mobility. Higher Education, 48, 55-78.

Nordensvard, J., Zhou, Y., \& Zhang, X. (2018). Innovation core, innovation semi-periphery and technology transfer: The case of wind energy patents. Energy Policy, 120, 213-227.

Pietrucha, J. (2018). Country-specific determinants of world university rankings. Scientometrics, 114, 1129-1139.

Prebisch, R. (1959). Commercial policy in the underdeveloped countries. The American Economic Review, 49(2), 251-273.

Price, D. J. S. (1965). Networks of scientific papers. Science, 49, 510-515.

Salager-Meyer, F. (2008). Scientific publishing in developing countries: Challenges for the future. Journal of English for Academic Purposes, 7(2008), 121-132.

Schofer, E., \& Meyen, J. W. (2005). The worldwide expansion of higher education in the twentieth century. American Sociological Review, 70(6), 898-920.

Schott, T. (1998). Ties between center and periphery in the scientific world-system: Accumulation of rewards, dominance, and self-reliance in the center. Journal of World-Systems Research, 4, $112-144$.

Shenhav, Y. A. (1986). Dependency and compliance in academic research infrastructures. Sociological Perspectives, 28(1), 29-51.

Smith, G. D., Turner, C. S., Osei-Kofi, N., \& Richards, S. (2004). Interrupting the usual: Successful strategies for hiring diverse faculty. The Journal of Higher Education, 75(2), 133-160.

Thomas, G. M., Meyer, J. W., Ramirez, F. O., \& Boli, J. (1987). Institutional structure: Constituting state, society, and the individual. Newbury Park, CA: SAGE.

Thompson, P., \& Diani, G. (2015). English for academic purposes. Approaches and implications. Cambridge: Cambridge Scholars Publishing.

Tomlinson, G., \& Freeman, S. (2018). Who really selected you? Insights into faculty selection processes in top-ranked higher education graduate programmes. Journal of Further and Higher Education, 42(6), 855-867.

Wallerstein, I. (1983). Labor in the world social structure. London: Sage.

Wallerstein, I. (1999). The end of the world as we know it. Social science for the twenty-first century. Minneapolis: University of Minnesota Press.

Wallerstein, I. (2004). World systems analysis. An introduction. Durham: Duke University Press.

Wallerstein, I. (2006). European universalism: The rhetoric of power. New York: The New Press. 
Wiedemann, T., \& Meyen, M. (2016). Internationalization through Americanization: The expansion of the international communication association's leadership to the world. International Journal of Communication, 10, 1489-1509.

Williamson, I. O., \& Cable, D. M. (2003). Predicting early career research productivity: The case of management faculty. Journal of Organizational Behavior, 24, 25-44.

Wu, H., \& Zha, Q. (2018). A new typology for analyzing the direction the direction of movement in higher education internationalization. Journal of Studies in International Education, 22, 1-19.

Zanotto, S., Haeffner, C., \& Guimaraes, J. (2016). Unbalanced international collaboration affects adversely the usefulness of countries' scientific output as well as their technological and social impact. Scientometrics, 109, 1789-1814. 